\title{
As atividades no campo da Terapia Ocupacional: mapeamento da produção científica dos terapeutas ocupacionais brasileiros de 1990 a 2008
}

\section{Activities in the field of Occupational Therapy: mapping the scientific production of Brazilian occupational therapists between 1990 and 2008}

\author{
Elizabeth M. F. Araújo Lima ${ }^{1}$, Marina Di Napoli Pastore ${ }^{2}$, \\ Danielle Guimarães Okuma ${ }^{3}$
}

\begin{abstract}
LIMA, E. M. F. A.; PASTORE, M. N.; OKUMA, D. G. As atividades no campo da Terapia Ocupacional: mapeamento da produção científica dos terapeutas ocupacionais brasileiros de 1990 a 2008. Rev. Ter. Ocup. Univ. São Paulo, v. 22, n. 1, p. 68-75, jan./abr. 2011.

RESUMO: As atividades são instrumento privilegiado das ações dos terapeutas ocupacionais e constituem o elemento orientador na construção complexa e contextualizada do processo terapêutico. No entanto, diferentes formas de conceber e definir atividades convivem, atualmente, na produção teórica na área, o que fica explicitado na variação em relação aos termos utilizados pelos terapeutas ocupacionais para nomear sua ferramenta de trabalho e seu objeto de estudo. Este artigo apresenta uma pesquisa bibliográfica desenhada para avaliar o estado da arte da produção científica dos terapeutas ocupacionais brasileiros a respeito das atividades e ocupações, considerando o uso dos termos, as concepções a eles vinculadas, suas definições, categorias e contexto e as diferentes abordagens na Terapia Ocupacional brasileira contemporânea. O recorte inicial, cujos resultados são aqui apresentados, delimitou artigos publicados em periódicos nacionais da área de 1990 a 2008. 206 artigos foram encontrados em cinco publicações nacionais na área e foi realizada análise quantitativa deste material. Com a realização do levantamento bibliográfico e a análise dos dados foi possível apontar tendências e interesses na produção dos terapeutas ocupacionais no Brasil, mapear os termos mais utilizados, os domínios das atividades mais freqüentemente abordados e sua articulação com as perspectivas teórico-metodológicas.
\end{abstract}

DESCRITORES: Atividades humanas; Publicações periódicas; Literatura de revisão como assunto; Terapia ocupacional.

\footnotetext{
* Este artigo é resultado de pesquisa realizada com apoio do Programa Ensinar com Pesquisa da Pró-Reitoria de Graduação da USP, durante os anos de 2007 e 2009. Parte dos resultados dessa pesquisa foi apresentada no XV Congress of the World Federation of Occupational Therapists, realizado em Santiago, Chile, em maio de 2010.

1. Doutora em Psicologia Clínica pela Pontifícia Universidade Católica de São Paulo. Pós-doutora pela University of the Arts, London, Reino Unido. Docente do Curso de Terapia Ocupacional do Departamento de Fisioterapia, Fonoaudiologia e Terapia Ocupacional, Faculdade de Medicina da Universidade de São Paulo (USP), integrante do Laboratório de Estudos e Pesquisa Arte, Corpo e Terapia Ocupacional.

2. Estudante do Curso de Terapia Ocupacional do Departamento de Fisioterapia, Fonoaudiologia e Terapia Ocupacional, Faculdade de Medicina da Universidade de São Paulo (USP), integrante do Laboratório de Estudos e Pesquisa Arte, Corpo e Terapia Ocupacional.

3. Terapeuta Ocupacional formada pela Universidade de São Paulo (USP), integrante do Laboratório de Estudos e Pesquisa Arte, Corpo e Terapia Ocupacional.
}

Endereço para correspondência: Elizabeth Maria Freire de Araújo Lima. Rua Cipotânea, 51. CEP.: 05360-000 - São Paulo, SP. e-mail: beth.lima@usp.br 


\section{INTRODUÇÃO}

6 As atividades humanas são instrumento privilegiado das ações dos terapeutas ocupacionais e constituem o elemento centralizador e orientador na construção complexa e contextualizada do processo terapêutico neste campo". (USP, 1997). Além disso, a atividade do sujeito, sua ação ou ocupação figuram no centro de uma busca de definição teórica da profissão e se apresentam como conceitos que unificariam ou criariam um contorno para o campo, que é marcado por práticas e saberes diversos. O território profissional no qual os terapeutas ocupacionais se reconhecem e do qual partem para construir suas propostas de intervenção é constituído em torno dessas noções que, no entanto, já apresentam em suas diferentes definições, concepções e abordagens, a multiplicidade constitutiva do próprio campo. (NASCIMENTO, 1990; SOARES, 1991; LIMA, 1997; CARLO; BARTALOTTI, 2001; MEDEIROS, 2003).

Apesar da polivocidade dos termos, na Terapia Ocupacional (TO) brasileira, a partir de um certo ponto do desenvolvimento da profissão, o conceito de atividade se universalizou, colocando sob o espectro de interesse deste campo questões relativas ao cotidiano, ao lazer e às atividades expressivas, criativas e produtivas. Este conceito, segundo Galheigo (1988, p. 68) foi "revisto, criticado transformado, mas nunca abolido". A autora acredita que,

para os terapeutas ocupacionais é necessário discutir sobre as causas que transformaram o trabalho, o jogo, as atividades em geral em instrumentos terapêuticos assim como as variações que sofreram ao longo dos tempos (p. 1).

No entanto, diferentes formas de conceber e atuar com as atividades convivem, no contemporâneo, nas mais diversas práticas em TO e termos como ocupação, fazer e ação coexistem na literatura com o termo atividade. A diversidade das experiências em TO, sem uma clareza de suas diferenças conceituais, e o uso dos diferentes termos sem uma explicitação de sua compreensão, dificulta a descriminação de diferentes perspectivas teóricas no interior da área.

Falcão e Guimarães (2004) apontam a dificuldade que os terapeutas ocupacionais têm tido em categorizar as atividades em virtude das diferentes denominações atribuídas pelos profissionais.

Galheigo identificou que até 1988 existiam poucos textos de Terapia Ocupacional publicados no Brasil e que a formação do profissional fazia-se por meio de bibliografia estrangeira e o conhecimento produzido no país era transmitido pela comunicação oral. Estudos a respeito das atividades utilizadas, seus métodos e concepções teóricas, bem como sobre as realizações dos pacientes atendidos também eram escassos (GALHEIGO, 1988).

$\mathrm{Na}$ época Galheigo alertou para o risco de que a TO se mostrasse uma prática sem teoria ou uma teoria sem prática e propôs aos profissionais que empreendessem a (re)construção de sua teoria e a crítica de sua prática. Seu estudo estava enraizado em seu tempo apontando para o porvir, pois foi a partir da década de 90 que a produção bibliográfica brasileira no campo da Terapia Ocupacional começou a ganhar consistência e expressar inquietações.

Hoje, passados 20 anos, o panorama é outro: a área conta com publicações científicas regulares, houve aumento significativo do número de cursos de Terapia Ocupacional, incremento da capacitação docente, e ampliação e consolidação da produção científica.

Neste sentido empreendemos uma pesquisa bibliográfica que tomou como objeto a produção científica dos terapeutas ocupacionais brasileiros, com o objetivo de investigar de que modo as atividades têm sido pensadas e teorizadas na produção desses profissionais desde o início dos anos 1990.

Este estudo teórico-conceitual busca fortalecer as bases teóricas da Terapia Ocupacional e explicitar seu estado de arte no que diz respeito à produção sobre atividades. Tem relevância pedagógica, ao produzir subsídios para a formação de alunos de graduação; profissional, podendo vir a contribuir para uma melhor definição das fronteiras conceituais da profissão; técnica e assistencial, no sentido de contribuir para a análise crítica das práticas com atividades e para o desenvolvimento de métodos e técnicas para sua utilização.

\section{PROCEDIMENTOS METODOLÓGICOS}

A pesquisa consistiu na realização de revisão bibliográfica sobre a temática das atividades em Terapia Ocupacional, através de artigos publicados no Brasil em periódicos da área.

O período selecionado, de 1990 a 2008, foi definido por meio de pesquisa preliminar, em particular das informações obtidas nas pesquisas de Galheigo (1988) e Emmel e Lancman (1998) que apontam para o incremento da produção teórica e da capacitação docente no campo da Terapia Ocupacional a partir da década de 1990. Este foi o 
LIMA, E. M. F. A. et al. As atividades no campo da TO Rev. Ter. Ocup. Univ. São Paulo, v. 22, n. 1, p. 68-75, jan./abr. 2011.

período em que se consolidou a virada conceitual e prática da profissão em curso desde o início da década de 1980, quando se pode observar um forte movimento no campo da Terapia Ocupacional no sentido de criar formas de atuação e intervenção a partir do compromisso ético e político com as pessoas atendidas (BRUNELLO et al., 2001).

Foram consultados os seguintes periódicos nacionais da área de Terapia Ocupacional: Cadernos de Terapia Ocupacional do Grupo de Estudos Profundos de TO (GES.TO), Cadernos de Terapia Ocupacional da UFSCar, Revista de Terapia Ocupacional da Escola Bahiana de Medicina e Saúde Pública, Revista do Centro de Estudos de Terapia Ocupacional (CETO) e Revista de Terapia Ocupacional da USP. Foi possível acessar todos os números da Revista de Terapia Ocupacional da Universidade de São Paulo desde do $1^{\circ}$ volume de 1990 até vol 19 n. 3 de 2008; todos os números dos Caderno de Terapia Ocupacional da UFSCAR desde do $1^{\circ}$ volume 1992 até vol 16 n.1 de 2008; e, todos os volumes da Revista do CETO, do primeiro volume de 1998 ao volume XI de 2008. Dos Cadernos de Terapia Ocupacional do GES.TO, foram consultados os volumes II, III, V, VII, X, XI e XVI, de 1990 a 2004, alguns obtidos em contato direto com o Grupo; da Revista de Terapia Ocupacional da Escola Bahiana, foram consultadas os volumes I, II e III de 2004, 2005 e 2007.

Considerando que a maior parte desses periódicos não está indexada realizamos uma busca de termos nos títulos, resumos e palavras-chaves de todos os artigos publicados nestas revistas no período proposto, com vistas a selecionar os artigos que tratassem de questões no campo das atividades em Terapia Ocupacional.

Os termos utilizados na busca foram: atividade(s) e termos correlatos tais como ocupação(ões), fazer(es), ação(ões); nome de atividades especificadas (pintura, dança, marcenaria, etc.); domínio das atividades (arte, lazer, trabalho, cotidiano, etc.); categorias de atividades (artísticas, corporais, produtivas, de lazer, lúdicas, do cotidiano, AVD/AVP e outros); ou aspectos das atividades (criatividade, expressão, comunicação, linguagem e outros).

No levantamento inicial foram encontrados 231 artigos, nos quais foi realizada uma leitura exploratória (GIL, 2002) que permitiu selecionar 206 de interesse para a pesquisa. Nesta primeira etapa foram descartados 25 artigos considerados fora do recorte da pesquisa por serem escritos por outros profissionais, por serem traduções de textos publicados originalmente em outra língua ou por não tratarem de questões do campo das atividades em TO.
Nos 206 textos selecionados, foi realizada leitura em profundidade e fichamento que possibilitou o registro ordenado do material. Através desta organização pudemos sintetizar as informações contidas nas fontes, identificar as idéias-chave e estabelecer uma organização que permitiu mapear nesta produção os tipos de textos presentes, as referências teórico-metodológicas mais utilizadas, os termos mais freqüentes e os domínios das atividades mais tematizados.

Para empreender a análise quantitativa dos dados, dividimos inicialmente os textos por ano de publicação e posteriormente os agrupamento em 4 períodos (de 1990 a 1995, de 1996-2000 de 2001 a 2005; e 2006 a 2008) com o intuito de estudar esta produção de forma longitudinal e observar as modificações e tendências nas formas de abordagem, nos termos utilizados e mesmo no interesse pela temática.

Apresentamos a seguir os resultados da primeira etapa da pesquisa caracterizada pela análise quantitativa dos dados.

\section{RESULTADOS E ANÁLISE}

\section{Os textos selecionados}

Ao trabalharmos com os dados agrupados nos quatro períodos acima descritos pudemos observar que a média de artigos por ano aumentou consideravelmente. De 7 artigos nos 6 primeiros anos do período estudado, num total de 43 artigos, esse número subiu para 9 artigos anuais no segundo período e para 15 artigos anuais entre os anos de 2001 a 2008, com 72 artigos no terceiro período (2001-2005) e 45 artigos no quarto período (2006-2008). Estes dados confirmam o incremento da produção bibliográfica dos terapeutas ocupacionais brasileiros, acompanhado por um aumento do montante dos textos que tratam de atividade, assinalando a continuidade do interesse pela questão das atividades no campo da Terapia Ocupacional.

\section{Tipo de Textos}

Dentre os 206 artigos selecionados, constatamos que $26 \%$ são textos de análise e ensaios teóricos; $46 \%$ apresentam experiências práticas, sendo que, destes, $74 \%$ trazem uma análise da experiência através de uma abordagem reflexiva, com contribuições teóricas. Por fim, $28 \%$ dos textos apresentam resultados de pesquisa (Tabela 1). 
LIMA, E. M. F. A. et al. As Atividades no Campo da TO Rev. Ter. Ocup. Univ. São Paulo, v. 22, n. 1, p. 68-75, jan./abr. 2011.

Tabela 1 - Distribuição dos artigos segundo tipo de texto encontrado

\begin{tabular}{lcc}
\hline \multicolumn{1}{c}{ Tipos de textos } & Quantidade numérica & Porcentagem \\
\hline Relatos de experiência com discussão teórica & 70 & $34 \%$ \\
Resultados de Pesquisa & 59 & $28 \%$ \\
Textos Teóricos & 53 & $26 \%$ \\
Relatos de experiência & 24 & $12 \%$ \\
\hline \multicolumn{1}{c}{ Total } & 206 & $100 \%$ \\
\hline
\end{tabular}

Vemos que os textos que apresentam experiências práticas - em sua maioria relatos de caso, descrição de experiências didáticas, clínicas e/ou institucionais -, representam uma porcentagem significativa, sendo que a maior parte deles traz uma reflexão teórica acompanhando o relato de experiência, indicando a importância da reflexão sobre a prática dos terapeutas ocupacionais. No entanto, observamos uma tendência à diminuição da freqüência destes textos em relação à produção total estudada. Nos primeiro e segundo períodos, respectivamente, $49 \%$ e $68 \%$ dos artigos selecionados em cada um dos períodos eram de relatos de experiência. Já entre 2001 e 2008, os artigos que apresentam experiências práticas, representam um montante menor em relação ao total de textos do período, em torno de $30 \%$.

É importante, salientar que mais de $25 \%$ dos textos estudados apresentam resultados de pesquisa, sendo que a maior parte deles (81\%) foi publicada entre os anos de 2001 e 2008, indicando um aumento significativo da publicação de pesquisas no campo. Entre 1990 a 1995 eles representavam 9,3\% dos textos do período; de 1996 a 2000 essa porcentagem subiu para 15\%, e entre 2001 e 2008 as pesquisas chegam a $42 \%$ dos textos do período.

\section{Termos utilizados}

Os textos selecionados para a pesquisa abordam

Tabela 2 - Número de artigos nos quais aparece cada um dos termos

\begin{tabular}{ccc}
\hline Termos mais utilizados & $\begin{array}{c}\text { Quantidade } \\
\text { numérica }\end{array}$ & Porcentagem \\
\hline Atividade & 188 & $91 \%$ \\
Ação & 77 & $37 \%$ \\
Ocupação & 34 & $17 \%$ \\
Fazer & 89 & $43 \%$ \\
\hline
\end{tabular}

de diferentes maneiras, e a partir de múltiplos recortes, as atividades, ocupações, fazeres e ações no campo da TO. Ao estudá-los procuramos investigar quais são os termos mais utilizados pelos terapeutas ocupacionais brasileiros para denominar seu instrumento de intervenção, e os domínios das atividades que são tematizados nas publicações. Dentre eles, o que tem maior evidência é o termo atividade, ora usado associado a outros termos, ora utilizado de forma exclusiva, seguido dos termos fazer, ação e ocupação, que aparecem, quase que na totalidade dos textos, associados a outros termos, sendo que na grande maioria dos textos, estão associados ao termo atividade (Tabela 2 e 3 ).

Confirma-se assim, a tendência apontada por Galheigo, em 1988, de universalização do conceito atividade na Terapia Ocupacional brasileira.

Tabela 3 - Número de artigos em que os termos aparecem como termo único ou associado a outros termos

\begin{tabular}{lcc}
\hline \multicolumn{1}{c}{ Termos mais utilizados } & $\begin{array}{c}\text { Quantidade } \\
\text { numérica }\end{array}$ & Porcentagem \\
\hline $\begin{array}{l}\text { Atividade como termo único } \\
\text { Atividade associada a outros }\end{array}$ & 55 & $27 \%$ \\
termos & 133 & $64 \%$ \\
$\begin{array}{l}\text { Ação como termo único } \\
\text { Ação associada a outros }\end{array}$ & 2 & $1 \%$ \\
termos & 75 & $36 \%$ \\
$\begin{array}{l}\text { Ocupação como termo único } \\
\text { Ocupação associada a outros } \\
\text { termos }\end{array}$ & 1 & $0,5 \%$ \\
$\begin{array}{l}\text { Fazer como termo único } \\
\text { Fazer associado a outros } \\
\text { termos }\end{array}$ & 13 & $16 \%$ \\
\hline
\end{tabular}

\section{Domínio das atividades}

Quanto aos domínios ou áreas das atividades, são em maior número os artigos que apresentam ou tematizam 
LIMA, E. M. F. A. et al. As atividades no campo da TO Rev. Ter. Ocup. Univ. São Paulo, v. 22, n. 1, p. 68-75, jan./abr. 2011.

o cotidiano, seguidos dos que trazem discussões sobre trabalho, lazer, lúdico, arte e cultura. Alguns textos abordam mais de uma área, enquanto $24 \%$ dos textos não fazem referência a nenhuma delas (Tabela 4).

Tabela 4 - Distribuição dos artigos segundo o domínio de atividades abordado

\begin{tabular}{lcc}
\hline \multicolumn{1}{c}{ Campo das atividades } & Quantidade numérica & Porcentagem \\
\hline Cotidiano & 77 & $37 \%$ \\
Arte e Cultura & 43 & $20 \%$ \\
Trabalho & 52 & $25 \%$ \\
Lazer e Lúdico & 46 & $22 \%$ \\
s/ referência a área de atividades & 50 & $24 \%$ \\
\hline
\end{tabular}

A partir do estudo dos textos, pudemos perceber que dois desses domínios das atividades colocam hoje novas questões para o campo da TO. Em alguns textos cotidiano e cultura são trabalhados não como domínio ou área das atividades humanas, mas como contexto nos quais todas as atividades humanas se desenrolam. (BARROS et al., 2004; BENNETON et al., 2003; GALHEIGO, 2003). Nesse sentido, poderíamos pensar que o cotidiano seria uma construção singular de cada sujeito, composta de atividades das diferentes áreas. A cultura por sua vez, seria o universo no qual se constitui e se desenvolve toda atividade humana, o espaço coletivo onde as atividades ganham significação.

\section{Perspectivas teórico-metodológicas}

Dos 206 textos estudados, apenas 15\% (30 textos) não apresentam perspectivas teórico-metodológicas que sustentem concepções ou discussões sobre atividades, subsidiem a reflexão teórica que acompanha as práticas, e/ou contribuam para a construção de uma teoria e uma crítica dessas práticas.

O restante, 176 textos, trazem perspectivas teóricometodológicas que referenciam a reflexão e a discussão apresentadas, sendo que em muitos deles estas perspectivas aparecem combinadas entre si.

Mângia e Nicácio (2001) apontam, que na atualidade a perspectiva socioterápica, a da psicodinâmica e a da desinstitucionalização constituem referenciais adotados no Brasil no campo da Terapia Ocupacional em Saúde Mental. Para as autoras a perspectiva socioterápica privilegia o campo relacional e a transformação da dinâmica institucional; as abordagens psicodinâmicas buscam a construção e reconstrução das histórias de vida; e a desinstitucionalização tem como perspectiva a desconstrução da lógica manicomial e a re-invenção de possibilidades subjetivas, sociais, culturais e materiais de estar no mundo.

Nos textos que abordam as questões das atividades no campo da Terapia Ocupacional foi possível observar a presença desses referenciais. No entanto o levantamento realizado não se referia a uma área específica de atuação profissional, o que levou a um espectro maior de referenciais adotados. Para organizar e apresentar o conjunto das perspectivas teórico-metodológicas encontradas buscamos acompanhar a forma como os terapeutas ocupacionais tem nomeado seus referências e agrupá-las por proximidade de autores e campos teóricos. Desta forma, organizamos os referenciais encontrados nas seguintes categorias: a perspectiva da desinstitucionalização; as abordagens psicodinâmicas; as abordagens sócio-antropológicos, e os textos referenciados em sistemas ou teorias filosóficas. Por fim, nos pareceu interessante evidenciar o aporte de modelos e métodos construídos no campo da Terapia Ocupacional.

A sistematização mais aprofundada das perspectivas teórico-metodológicas no campo da Terapia Ocupacional mostrou-se necessária e aguarda novas pesquisas que discutam as bases epistemológicas do campo.

Nos textos estudados, aqueles que apresentam uma discussão referenciada em teorias filosóficas, são em número de 23 , representando $13 \%$ dos textos que apresentam alguma perspectiva teórica-metodológica. Quase metade deles fundamenta-se na perspectiva do materialismo histórico, algumas vezes articulada à perspectiva da desinstitucionalização. Nesta categoria figuram também os artigos com fundamentação nas teorias da complexidade, nas filosofias da diferença e nas teorias da estética.

A perspectiva da desinstitucionalização aparece em $13 \%$ dos textos que apresentam perspectiva teórica. A maior parte desses textos aborda estudos na área de Saúde Mental e muitos deles trazem discussões sobre políticas públicas na área da saúde.

Textos com perspectivas sócio-antropológicas, incluindo abordagens sociológicas, antropológicas, das teorias sócio-interacionistas, da economia solidária e do cooperativismo, somam um total de $14 \%$ dos textos com 
perspectivas teórico-metodológicas, aparecendo, em sua maioria, combinadas com outras perspectivas. Cerca de 1/3 desses textos refere-se a discussões e atuações no campo da Terapia Ocupacional Social.

As abordagens psicodinâmicas, de inspiração psicanalítica ou de outras teorias psicológicas, aparecem em $22 \%$ dos textos que apresentam perspectivas teóricometodológicas, sendo, na maioria desses textos, a perspectiva predominante. É interessante apontar que dentre as linhas psicológicas e psicanalíticas, a perspectiva winnicottiana é a mais freqüentemente referida nos textos estudados. Entre os textos de abordagem psicodinâmica, destacamos aqueles referenciados na psicodinâmica do trabalho, por apresentarem um referencial particular que vem crescendo no campo nos últimos 10 anos.

Por fim, métodos e técnicas desenvolvidos no campo da Terapia Ocupacional subsidiam os estudos, são apresentados ou discutidos em $29 \%$ dos textos que trazem alguma perspectiva teórico-metodológica, Entre esses métodos ou modelos encontra-se o Método Críticolaborativo das Relações Humanas, proposto por Rui Chamone; o Modelo da Terapia Ocupacional Dinâmica, proposto por Maria José Benetton; o Modelo Canadense de Desempenho Ocupacional, o Modelo da Ocupação Humana e o Modelo Ecológico. É importante salientar que todos os textos que se fundamentam no Método Crítico-laborativo foram publicados na Revista do GES.TO. Em relação aos textos que trabalham com a perspectiva do Modelo da TO Dinâmica, denominada nos textos publicados até 2001 de Terapia Ocupacional Psicodinâmica, $80 \%$ deles foi publicado na Revista do CETO.

Entre as outras perspectivas encontradas na pesquisa dos textos, destacamos as abordagens corporais e as teorias e técnicas de grupo, por representarem um montante significativo e indicarem perspectivas singulares no campo.

A Tabela 5 traz a distribuição percentual destas perspectivas teórico-metodológicas.

Tabela 5 - Porcentagem e quantidade numérica dos textos que apresentam perspectivas teórico-metodológicas, tanto predominante quanto combinada a outras perspectivas

\begin{tabular}{|c|c|c|c|}
\hline \multirow{2}{*}{\multicolumn{2}{|c|}{$\begin{array}{l}\text { Perspectivas } \\
\text { Teórico-Metodológicas }\end{array}$}} & \multicolumn{2}{|c|}{ TOTAL } \\
\hline & & Quantidade & Porcentagem \\
\hline \multirow[b]{2}{*}{ Bases filosóficas } & Materialismo Histórico & 11 & \multirow[b]{2}{*}{$13 \%$} \\
\hline & Outros & 12 & \\
\hline \multicolumn{2}{|c|}{ Perspectiva da Desinstitucionalização } & 22 & $13 \%$ \\
\hline \multicolumn{2}{|c|}{ Abordagens Sócio-antropológicas } & 24 & $14 \%$ \\
\hline \multirow{2}{*}{$\begin{array}{l}\text { Abordagens } \\
\text { Psicodinâmicas }\end{array}$} & $\begin{array}{l}\text { Inspiração psicanlítica / } \\
\text { outras psicologias }\end{array}$ & 23 & \multirow[b]{2}{*}{$22 \%$} \\
\hline & Psicodinamica do Trabalho & 15 & \\
\hline \multirow{3}{*}{$\begin{array}{l}\text { Modelos e Métodos } \\
\text { de Terapia Ocupacional }\end{array}$} & Modelo TO Dinamica & 30 & \multirow{3}{*}{$29 \%$} \\
\hline & Met Crítico-laborativo & 12 & \\
\hline & Outros & 9 & \\
\hline \multirow{3}{*}{ Outras } & Abordagens Corporais & 11 & \multirow{3}{*}{$15 \%$} \\
\hline & Teorias e Técnicas de Grupo & 07 & \\
\hline & Outras & 09 & \\
\hline \multicolumn{2}{|c|}{$\begin{array}{l}\text { Total de textos que apresentam perspectiva } \\
\text { teórico-metodológica }\end{array}$} & \multicolumn{2}{|c|}{176} \\
\hline
\end{tabular}

\section{CONSIDERAÇÕES FINAIS}

A realização desta etapa da pesquisa, caracterizada pela análise quantitativa dos dados, possibilitou a visualidade sobre a produção teórica dos terapeutas ocupacionais brasileiros, relativa aos usos e concepções das atividades, 
LIMA, E. M. F. A. et al. As atividades no campo da TO Rev. Ter. Ocup. Univ. São Paulo, v. 22, n. 1, p. 68-75, jan./abr. 2011.

e a indicação de tendências e interesses nesta produção. Com este estudo pudemos apontar os termos mais utilizados para designar as ferramentas de intervenção ou objetos de estudo da área, os domínios das atividades trabalhados e as perspectivas teórico-metodológicas que subsidiam as reflexões sobre as atividades e seus usos no campo.

O mapeamento dos termos utilizados e os dados obtidos nos levou ao estudo das definições mais freqüentes para os termos, as discussões em torno desses termos e sua significação para o campo. Dos 206 artigos estudados, 92 foram selecionados para serem examinados em profundidade na análise qualitativa, que será apresentada em outra oportunidade. Quando diferentes concepções e formas de trabalhar com atividades são expressas, podemos produzir uma compreensão melhor e mais aprofundada das práticas e abordagens teóricas no campo.

LIMA, E. M. F. A.; PASTORE, M. N.; OKUMA, D. G. Activities in the field of Occupational Therapy: mapping the scientific production of Brazilian occupational therapists between 1990 and 2008. Rev. Ter. Ocup. Univ. São Paulo, v. 22, n. 1, p. 68-75, jan./abr. 2011.

\begin{abstract}
Occupation and activities are important tools to occupational therapists and participate on the construction of therapeutic process. Different concepts of activities are present in the Brazilian theoretical production, what is expressed on the multiplicity of terms used by occupational therapists to name their tool and object of study. This inquiry is a bibliographical revision designed to evaluate the state of the art of the Brazilian occupational therapists' scientific production about activities and occupation, considering the use of terms and conceptions, their definitions, categories and contexts and different approaches in the contemporary Occupational Therapy. The initial clipping delimited articles published in national journals from 1990 to 2008. 206 articles that discussed the activities in Occupational Therapy had been found in five national publications of the area. All these articles were analyzed quantitatively. With the accomplishment of the bibliographical survey and analysis of the data, it was possible to point out trends and interests in the theoretical production of the Brazilian occupational therapists, map the terms more often used, the conceptions and activities domains most frequent, and their joint to theoretical-methodological perspectives.
\end{abstract}

KEY WORDS: Human activities; Periodicals; Review literature as topic; Occupational therapy.

\title{
REFERÊNCIAS
}

BARROS, D. D.; GHIRARDI, M. I.; LOPES, R. E. Terapia ocupacional social. Revista de Terapia Ocupacional da Universidade de São Paulo, v. 13, n. 3, p. 95-103, 2002.

BENETTON, J.; FERRARI, S. M. L.; TEDESCO, S. Hábitos, cotidiano e terapia ocupacional. Revista CETO, v. 8, n..8, p. $27-$ 40, 2003.

BRUNELlO, M. I. B.; CASTRO, E. D.; LIMA, E. M. F. A. Atividades humanas e terapia ocupacional. In: CARLO, M. M. R. P.; BARTALOTTI, C. C. (Org.). Terapia ocupacional no Brasil: fundamentos e perspectivas. São Paulo: Plexus Editora, 2001. p. 41-62.

CARLO, M. M. R. P.; BARTALOTTI, C. C. Caminhos da terapia ocupacional. In: CARLO, M. M. R. P.; BARTALOTTI, C. C. (Org.). Terapia ocupacional no Brasil: fundamentos e perspectivas. São Paulo: Plexus Editora, 2001. p.19-40.

EMMEL, M. L. G.; LANCMAN, S. Quem são nossos mestres e doutores? O avanço da capacitação docente em Terapia Ocupacional no Brasil. Cadernos de Terapia Ocupacional da UFSCar, v. 7, n. 1, p. 29-38, 1998.

FALCÃO, I. V.; GUIMARÃES, D. S. L. Análise de atividades e formação do terapeuta ocupacional: um estudo com os preceptores de estágio da UFPE. Revista de Terapia Ocupacional da Universidade de São Paulo, v. 15, n. 2, p. 63-70, 2004.

GALHEIGO, S. Terapia Ocupacional: a produção do conhecimento e o cotidiano da prática sob o poder disciplinar: em busca de um depoimento coletivo. 1988. 84 f. Dissertação (Mestrado em Educação). Campinas: UNICAMP, 1988.

GALHEIGO, S. O cotidiano na terapia ocupacional: cultura, subjetividade e contexto histórico-social. Revista de Terapia Ocupacional da Universidade de São Paulo, v. 14, n. 3, p. 104109, 2003.

GIL, A. C. Como elaborar projetos de pesquisa. São Paulo: 
Atlas, 2002.

LIMA, E. M. F. A. Clínica e criação: a utilização de atividades em instituições de Saúde Mental. 1997. 201 f. Dissertação (Mestrado em Psicologia Clínica).São Paulo: PUC/SP, 1997.

MÂNGIA, E. F.; NICÁCIO, F. Terapia ocupacional em saúde mental: tendências principais e desafios contemporâneos. In: CARLO, M. M. R. P.; BARTALOTTI, C. C. (Org.). Terapia ocupacional no Brasil: fundamentos e perspectivas. São Paulo: Plexus Editora, 2001. p. 63-80.

MEDEIROS. M. H. R. Terapia Ocupacional. Um enfoque epistemológico e social. São Paulo: Ed. Hucitec; São Carlos:

Recebido para publicação: 24/10/10

Aceito para publicação: 10/05/11
EdUFSCar, 2003.

NASCIMENTO, B.A. O mito da atividade terapêutica. Revista de Terapia Ocupacional da Universidade de São Paulo, v.1, n. 1, p. 17-21, 1990.

SOARES, L.B. T. Terapia ocupacional: lógica do capital ou do trabalho? São Paulo: Hucitec, 1991.

USP. Universidade de São Paulo. Folder do Curso de Terapia Ocupacional da FMUSP. São Paulo: Centro de Docência e Pesquisa em Terapia Ocupacional do Departamento de Fisioterapia, Fonoaudiologia e Terapia Ocupacional da FMUSP, 1997. 